\title{
Physician and patient benefit-risk preferences from two randomized long-acting injectable antipsychotic trials
}

This article was published in the following Dove Press journal:

Patient Preference and Adherence

21 October 2016

Number of times this article has been viewed

\author{
Eva G Katz' \\ Brett Hauber ${ }^{2}$ \\ Srihari Gopal ${ }^{3}$ \\ Angie Fairchild ${ }^{2}$ \\ Amy Pugh ${ }^{4}$ \\ Rachel B Weinstein ${ }^{3}$ \\ Bennett S Levitan ${ }^{3}$ \\ 'Janssen Research \& Development, \\ LLC, Raritan, NJ, ${ }^{2}$ RTI Health \\ Solutions, Research Triangle Park, NC, \\ ${ }^{3}$ Janssen Research \& Development, \\ LLC, Titusville, NJ, ${ }^{4}$ The University \\ of California, San Francisco \\ (UCSF), CA, USA
}

Purpose: To quantify clinical trial participants' and investigators' judgments with respect to the relative importance of efficacy and safety attributes of antipsychotic treatments for schizophrenia, and to assess the impact of formulation and adherence.

Methods: Discrete-choice experiment surveys were completed by patients with schizophrenia and physician investigators participating in two phase-3 clinical trials of paliperidone palmitate 3-month long-acting injectable (LAI) antipsychotic. Respondents were asked to choose between hypothetical antipsychotic profiles defined by efficacy, safety, and mode of administration. Data were analyzed using random-parameters logit and probit models.

Results: Patients $(\mathrm{N}=214)$ and physicians $(\mathrm{N}=438)$ preferred complete improvement in positive symptoms (severe to none) as the most important attribute, compared with improvement in any other attribute studied. Both respondents preferred 3-month and 1-month injectables to oral formulation $(P<0.05)$, irrespective of prior adherence to oral antipsychotic treatment, with physicians showing greater preference for a 3-month over a 1-month LAI for nonadherent patients. Physicians were willing to accept treatments with reduced efficacy for patients with prior poor adherence. The maximum decrease in efficacy (95\% confidence interval [CI]) that physicians would accept for switching a patient from daily oral to 3-month injectable was as follows: adherent: 9.8\% (95\% CI: 7.2-12.4), 20\% nonadherent: $25.4 \%$ (95\% CI: $21.0-29.9$ ), and $50 \%$ nonadherent: $>30 \%$. For patients, adherent: $10.1 \%$ (95\% CI: $6.1-14.1$ ), nonadherent: the change in efficacy studied was regarded as unimportant.

Conclusion: Improvement in positive symptoms was the most important attribute. Patients and physicians preferred LAIs over oral antipsychotics, with physicians showing a greater preference for 3-month over 1-month LAI. Physicians and patients were willing to accept reduced efficacy in exchange for switching a patient from an oral formulation to a LAI.

Keywords: benefit-risk assessment, long-acting injectable, patient preference, physician preference, schizophrenia, survey

\section{Introduction}

Schizophrenia, a chronic and severe psychiatric disorder, impairs psychosocial functioning, significantly diminishes quality of life, and requires continuous, longterm antipsychotic treatment. ${ }^{1,2}$ Treatments should balance reducing psychotic and functional symptoms while minimizing treatment-induced adverse events (AEs). ${ }^{3}$ While clinical trials and observational studies provide information on the frequency of symptoms and events, benefit-risk decisions also require judging the clinical impact of these outcomes. These value judgments have traditionally been based on a physician's perspective, ${ }^{4}$ but there is increasing interest in using patient's input ${ }^{5-7}$
Correspondence: Eva G Katz Janssen Research \& Development, LLC, 920 US Highway 202 South,

I I36, Raritan, NJ 08869, USA

Tel +I 9082187015

Email ekatzl@its.jnj.com 
for clinical and regulatory decision-making. The US Food and Drug Administration (FDA) Center for Drug Evaluation and Research, ${ }^{8}$ the European Medicines Agency, and Health Canada have taken steps to better understand and incorporate patient perspectives in benefit-risk evaluations. ${ }^{9-11}$ The FDA Center for Devices and Radiological Health specifically recommended incorporating patient preference information into premarket review to inform benefit-risk assessment, ${ }^{9,12,13}$ a view strongly endorsed by several patient advocacy groups and public-private partnerships. ${ }^{14,15}$

Previous preference studies in schizophrenia, performed with online panels of psychiatrists and patients, demonstrated that schizophrenia patients were capable of completing such surveys, ${ }^{16,17}$ and that both physicians and patients place greater importance on improvements in positive symptoms than on improvements in negative symptoms or in avoiding treatment-related AEs (weight gain, extrapyramidal symptoms [EPS], hyperglycemia, and hyperprolactinemia). ${ }^{18,19}$ Patient adherence to oral antipsychotics was identified as an important factor in the assessment of oral versus injectable medicine formulations. ${ }^{20-22}$ For example, in pilot studies using online panels of patients and physicians, respondents preferred long-acting injectables (LAIs) over daily oral antipsychotics for hypothetical patients with past nonadherence to antipsychotics, though patients preferred the oral formulation for patients with high prior adherence. ${ }^{18,19}$ An important open question is whether the results of these pilot studies are reproducible in different samples, and particularly, whether the online panel results accurately reflect the preferences of schizophrenia patients who meet the clinical trial inclusion/ exclusion criteria. ${ }^{18,19}$

This paper describes the results of preference surveys administered to trial participants and physician investigators during two phase-3, multinational clinical studies (NCT01515423 and NCT01529515)23,24 of paliperidone palmitate 3-month (PP3M) formulation, a LAI antipsychotic. The objective of these surveys was to quantify patient and physician preferences related to benefits and risks of antipsychotic treatments for schizophrenia, and to assess the impact of past patient adherence on the relative importance of treatment efficacy and formulation.

\section{Methods}

Two discrete-choice experiment (DCE) surveys, one for patients with schizophrenia and one for psychiatrists treating such patients, were incorporated into Trial-1 (NCT01515423) and Trial-2 (NCT01529515) as a prespecified exploratory end point requirement within the clinical protocols
(Figures S1-S5). In both of these randomized double-blind multicenter trials, men and women, aged 18-70 years (inclusive), diagnosed with schizophrenia (Diagnostic and Statistical Manual of Mental Disorders, 4th Edition [DSM$I V-T R]$, criteria) for $>1$ year before screening, and with a total Positive and Negative Syndrome Scale (PANSS) score between 70 and $120(<120$ for Study 2$)$ at screening and baseline, were enrolled. Patients symptomatically stable on LAI antipsychotic treatments (including once-monthly PP [PP1M]) other than PP3M were eligible for study entry.

The key exclusion criteria were as follows: primary, active $D S M-I V$ diagnosis other than schizophrenia; significant risk of suicidal behavior; history of substance dependence within 6 months before screening; involuntary status in a psychiatric hospital at screening; history of neuroleptic malignant syndrome, tardive dyskinesia, or any malignancy in the previous 5 years, except for basal cell carcinoma. Detailed descriptions of the two trials have been published. ${ }^{20,21}$ These surveys were adapted from versions used in pilot studies conducted with patients and physicians sampled from online panels. ${ }^{18,19}$

\section{Preference surveys}

\section{Survey instruments}

Design and testing of the surveys are described in the pilot studies. ${ }^{18,19}$ Briefly, DCEs offer a systematic way to elicit trade-offs and quantify the relative importance of treatment attributes ${ }^{25}$ by asking respondents (physicians and patients) to evaluate which of the several hypothetical treatment profiles they judge to be more appropriate for a hypothetical patient in a series of choice questions. ${ }^{19}$ Preferences were estimated by regressing treatment choices on the systematically altered features of each treatment profile. ${ }^{26}$

The attributes were intended to incorporate aspects of treatment-related efficacy, safety, and mode of administration that patients and physicians take into account when choosing a therapy. The patient and physician surveys included analogous sets of attributes and levels, with labels adapted for each group of respondents. The first series of questions assessed the relative importance of three benefit attributes (improvements in positive symptoms, negative symptoms, and social functioning) and four risk (AEs) attributes (weight gain, EPS, hyperprolactinemia, and hyperglycemia). A second series of questions evaluated the effect of past patient adherence on preferences for the mode of administration (oral, 1-month LAI, 3-month LAI) and treatment efficacy. The physician survey also included the probability of EPS in the second series of questions. Each question in this series was asked with a primary and a follow-up question. First, respondents 
were asked to choose between treatments that could be administered to an adherent patient, ie, by pill or by injection, where the efficacy varied between treatments. Second, they were given additional information about the hypothetical schizophrenia patient's past history of missing doses of oral medications and then asked to choose between the same medications. To lessen patient respondent burden, patient respondents were only asked this second question if they chose the oral formulation initially.

\section{Survey participants}

\section{Physicians}

English-speaking physicians who participated either as a principal investigator or as a subinvestigator in two clinical trials, and had direct contact with patients, were invited to complete the web-based preference survey. Invitations were sent $\sim 3$ months after their site opened, to allow physicians to have experience with a 3-month LAI. Physicians were excluded if their English skills were insufficient for the survey.

\section{Patients}

English-speaking patients enrolled at study sites in Englishspeaking countries (Australia, Canada, and the USA) in both trials were administered the survey on a tablet computer during a scheduled visit. Patients were asked to complete the survey at week 13 or later to allow treatment experience with a LAI.

\section{Sample requirements}

Survey requirements were prespecified: respondents were required to complete at least one survey choice question and at least one response from each of the two columns (A or B) when all eight questions in the first set of tasks were completed. Additionally, patient survey duration of at least 7 minutes was prespecified for a valid attempt. If a patient survey did not meet the above-mentioned criteria, up to one retest was requested. Completed surveys that did not meet these requirements were excluded from the analyses.

The survey was administered during the maintenance phases of the trials; if the patient's condition was not stable enough (in the opinion of the investigator or site coordinator) to give sufficient attention to the survey during a scheduled visit, then the survey was scheduled for a subsequent visit. If the patient chose to withdraw from the study prior to study completion, then the patient was requested to complete the survey by the last visit, provided the study coordinator thought the patient would give the survey the required time and attention.
The survey and recruiting methods were approved by RTI International's Institutional Review Board. Development and testing of the surveys were conducted according to good research practices ${ }^{25,27}$ and involved key opinion leaders, physicians, and patients to ensure appropriateness of content. All patients were informed of their rights as survey participants. Patients provided an informed consent to participate in the survey by clicking "Yes, I agree to participate" in tablet devices. Physicians were exempt from providing informed consent.

\section{Statistical analysis}

Responses to the first series of choice questions were analyzed using a random-parameters logit model, where the choice of treatment profile was dependent upon attribute levels, specified as categorical effect-coded variables. The model estimated relative preference weights and importance scores for all attribute levels included in the surveys.

Physicians' responses to the second series of choice questions were analyzed using a bivariate-probit model that jointly considered respondents' answers to the primary and follow-up questions and estimated attribute-level weights that maximized the likelihood of both answers by respondents. ${ }^{26}$ For patients, preference weights for primary and follow-up questions were computed using separate probit models, and the standard errors for both the models were standardized to account for correlations between models post-estimation. Heterogeneity of the first set of preferences among predefined subgroups was examined using the Wald test. Physician subgroups included sex, region, years in practice, $\%$ of patients treated with LAIs, and perceived patient adherence. Patient subgroups included trial, age, baseline PANSS score, body mass index, employment status, previous experience with LAIs, and reported adherence.

Second-series preference weights were used to compute the mean maximum acceptable reduction in benefit that would offset increases in utility associated with changes in treatment formulation for hypothetical patients with different levels of past adherence. Both analyses were conducted using NLOGIT 4.0 (Econometric Software, Inc., Plainview, NY, USA).

The random-parameters logit and probit models produced unique preference weights for each attribute level. The difference between these weights for best and worst attribute levels can be interpreted as the overall mean relative importance associated with moving from the least preferred to the most preferred level of that attribute. ${ }^{5,7,28}$ In this study, the highest mean relative importance score from each model 
was assigned a value of 10 and was used to scale the mean relative importance for each of the other attributes.

\section{Results}

\section{Participant demographics} Physicians

Invitations to complete the survey were sent to 588 physicians; 60 did not meet the eligibility criteria and 76 were excluded due to language issues. A total of 452 physicians in 27 countries completed the survey and answered at least one choice question; however, 14 physicians selected the same response ( $\mathrm{A}$ or $\mathrm{B}$ ) for all eight choice questions in the first series and were thus excluded, leaving 438 physician surveys with usable data. Most of the respondent physicians were men $(n=255,58.5 \%)$, and $\sim 73 \%(n=318)$ had been practicing medicine for $\geq 10$ years. The respondent physicians were from broad geographical regions (Table 1).

\section{Patients}

The patient survey was a protocol requirement. However, patients who withdrew or relapsed prior to week 13 of the trial

Table I Demographic characteristics of physicians and patients

\begin{tabular}{lll}
\hline Physicians & & \\
\hline Question & Survey physicians & $(\mathbf{N}=\mathbf{4 3 8})$ \\
\cline { 2 - 3 } & $\mathbf{n}$ & $\%$ \\
\hline Sex & 255 & 58.5 \\
Men & 2 & 0.5 \\
Missing & & \\
Years in practice & 23 & 5.3 \\
$<$ I-3 & 95 & 21.8 \\
$4-9$ & 162 & 37.2 \\
I0-20 & 156 & 35.8 \\
$>21$ & 2 & 0.50 \\
Missing & 2 & \\
Average number of schizophrenia patients treated per month & \\
$<5$ & 9 & 2.1 \\
$5-20$ & 140 & 32.1 \\
$21-50$ & 150 & 34.4 \\
$51-100$ & 94 & 21.6 \\
$>100$ & 43 & 9.9 \\
Missing & 2 & 0.5
\end{tabular}

$\%$ of patients of these physicians who actually took oral antipsychotics as prescribed in the past month, as assessed by physicians

Mean \pm SD $\quad 68.5 \pm 15.5$

Missing 18

Region

Ukraine 7l

People's Republic of China $\quad 50$

USA 46

Russia $\quad 45$

Other $^{\mathrm{a}} 226$

4. 1

16.2

11.4

10.5

10.3

51.6

(Continued)
Table I (Continued)

\begin{tabular}{|c|c|c|c|c|}
\hline \multicolumn{5}{|l|}{ Patients } \\
\hline \multirow[t]{2}{*}{ Question } & \multicolumn{2}{|c|}{$\begin{array}{l}\text { Survey patients } \\
(N=2 \mid 4)\end{array}$} & \multicolumn{2}{|c|}{$\begin{array}{l}\text { Trial patients } \\
(\mathrm{N}=1,935)\end{array}$} \\
\hline & $\mathbf{n}$ & $\%$ & $\mathbf{n}$ & $\%$ \\
\hline Age (years), mean $\pm S D$ & $40.5 \pm 12.2$ & - & $38.4 \pm 11.7$ & - \\
\hline \multicolumn{5}{|l|}{ Sex } \\
\hline Men & 166 & 77.6 & 1,161 & 60.0 \\
\hline \multicolumn{5}{|l|}{ Race } \\
\hline White & 79 & 36.9 & I,077 & 55.7 \\
\hline Black or AA & 123 & 57.5 & 223 & 11.5 \\
\hline Asian & 3 & 1.4 & 554 & 28.6 \\
\hline Other & 7 & 3.3 & 77 & 4.0 \\
\hline Multiple & 2 & 0.9 & 4 & 4.0 \\
\hline BMI $\left(\mathrm{kg} / \mathrm{m}^{2}\right)$, mean $\pm \mathrm{SD}$ & $29.1 \pm 5.8$ & - & $26.5 \pm 5.1$ & - \\
\hline \multicolumn{5}{|c|}{ Age at first schizophrenia diagnosis (years) } \\
\hline Mean \pm SD & $26.6 \pm 10.1$ & - & $27.2 \pm 9.0$ & - \\
\hline $\begin{array}{l}\text { Total PANSS score, } \\
\text { mean } \pm \text { SD }\end{array}$ & $80.1 \pm 14.0$ & - & $82.6 \pm 13.2$ & - \\
\hline \multicolumn{5}{|c|}{ Preferences on frequency of medication ${ }^{\mathrm{b}}$} \\
\hline Every day & 23 & 10.7 & 62 & 3.2 \\
\hline Every month & 96 & 44.9 & 686 & 35.5 \\
\hline Every 3 months & 73 & 34.1 & 1,018 & 52.6 \\
\hline No preference & 15 & 7.0 & 161 & 8.3 \\
\hline Missing & 7 & 3.3 & 8 & 0.4 \\
\hline \multicolumn{5}{|c|}{ Preference between pills and injections ${ }^{\mathrm{b}}$} \\
\hline Pills & 128 & 59.8 & 433 & 22.4 \\
\hline Injection & 83 & 38.8 & $\mathrm{I}, 497$ & 77.4 \\
\hline Missing & 3 & 1.4 & 5 & 0.3 \\
\hline \multicolumn{5}{|l|}{ Civil status } \\
\hline Single & 37 & 17.3 & $\mathrm{n} / \mathrm{a}$ & - \\
\hline $\begin{array}{l}\text { Married/in a long- } \\
\text { term partnership }\end{array}$ & 48 & 22.4 & $\mathrm{n} / \mathrm{a}$ & - \\
\hline Widowed & 7 & 3.3 & $\mathrm{n} / \mathrm{a}$ & - \\
\hline Divorced & 17 & 7.9 & $\mathrm{n} / \mathrm{a}$ & - \\
\hline Missing & 105 & 49.1 & $\mathrm{n} / \mathrm{a}$ & - \\
\hline \multicolumn{5}{|c|}{ Taking a depot antipsychotic within 8 weeks prior to entering this study } \\
\hline Yes & 11 & 5.1 & 98 & 5.1 \\
\hline No & 94 & 43.9 & 295 & 15.2 \\
\hline Missing & 109 & 50.9 & 1,542 & 79.7 \\
\hline \multicolumn{5}{|l|}{ Region } \\
\hline USA & 199 & 93.0 & 325 & 16.8 \\
\hline Canada & 8 & 3.7 & 11 & 0.6 \\
\hline Australia & 7 & 3.3 & 7 & 0.4 \\
\hline Other & 0 & 0 & I,592 & 82.3 \\
\hline
\end{tabular}

Notes: alncludes Argentina, Australia, Belgium, Brazil, Bulgaria, Canada, Czech Republic, France, Germany, Greece, Hungary, Japan, Korea, Mexico, Poland, Portugal, Romania, Slovakia, Spain, and Taiwan. Each country represents $\leq 5 \%$ of physician respondents; "'Preference" in these questions is meant in the convention sense and not as a formal measure of patient preference.

Abbreviations: BMI, body mass index; $\mathrm{N}$, number of respondents who answered question; n/a, not applicable; PANSS, positive and negative syndrome scale; SD, standard deviation; AA, African-American.

were not administered the survey. Thirty-eight patients did not meet the prespecified survey requirements on the initial test; of whom 5 refused a retest and 19 had usable retest data. A total of 219 patients from the two clinical trials completed the survey and answered at least one choice question. Of those 
219 respondents, five patients who selected the same response (A or B) for all eight choice questions were excluded. The majority of patients who participated in the survey were men $(n=166,77.6 \%)$ and African-American $(n=123,57.5 \%)$ with a mean age of 40.5 years (Table 1 ), whereas the majority of trial patients were men $(60 \%)$ and white $(n=1,077,60 \%)$ with a mean age of 38.4 years.

\section{Benefit and risk trade-offs Physicians}

Analysis of the first series of choice tasks indicated that physicians considered complete improvement in positive symptoms (from no improvement to very much improved) as the most important attribute (Figure 1) and was assigned an importance value of 10 . Physicians appraised all remaining efficacy attributes (improved social functioning: 7.38; improved negative symptoms: 5.19) as more important than elimination of any of the side effects assessed (hyperglycemia: 2.38; EPS: 2.30; 15\% weight gain: 1.61; and hyperprolactinemia: 1.59 ). Physicians valued total improvement in negative symptoms (no improvement to very much improved) as approximately half as important as total improvement in positive symptoms (Figure 1).

\section{Patients}

Analysis of the first series of choice tasks indicated that patients considered complete improvement in positive symptoms (from severe to none) as the most important attribute (relative importance: 10) and was four times as important as any other efficacy endpoint (improved negative symptoms: 1.74; improved social functioning: 0.82) or AE (no weight gain: 2.18; no hyperglycemia: 1.96 ; no hyperprolactinemia: 1.76) assessed in the survey (Figure 2).

There were no statistically significant differences between the estimated preferences for the first series of choice questions for any of the physician or patient subgroups.

\section{Effect of formulation and adherence Physicians}

Physicians had higher preference for LAI over a daily pill $(P<0.05)$ for both adherent and nonadherent patients (Figure 3 ). Physicians preferred the 3-month over 1-month LAI for patients with a history of skipping $20 \%(P=0.02)$ and $50 \%(P=0.003)$ doses.

In exchange for switching an adherent patient from a daily oral to a 1-month LAI, physicians would be willing to accept up to a $8.9 \%$ (95\% confidence interval $[\mathrm{CI}]: 6.4-11.5)$ decrease

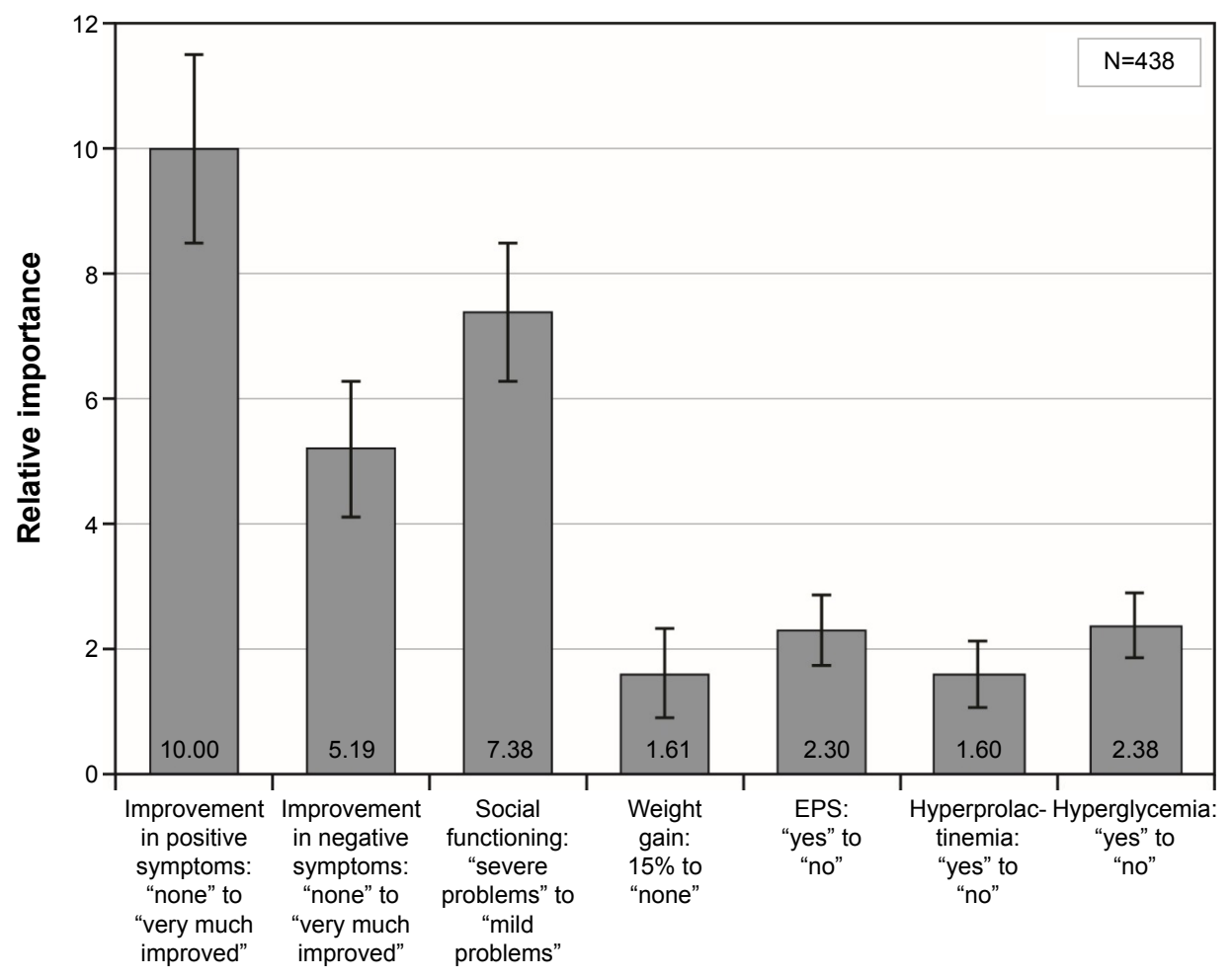

Figure I Preference weights for first series of choice questions for physicians.

Notes: Each bar represents the improvement in utility associated with switching from the least preferred to the most preferred level of each attribute. The vertical bars surrounding each mean preference weight denote the $95 \% \mathrm{Cl}$ about the point estimate.

Abbreviations: $\mathrm{Cl}$, confidence interval; EPS, extrapyramidal symptoms; $\mathrm{N}$, number of respondents who answered the question. 


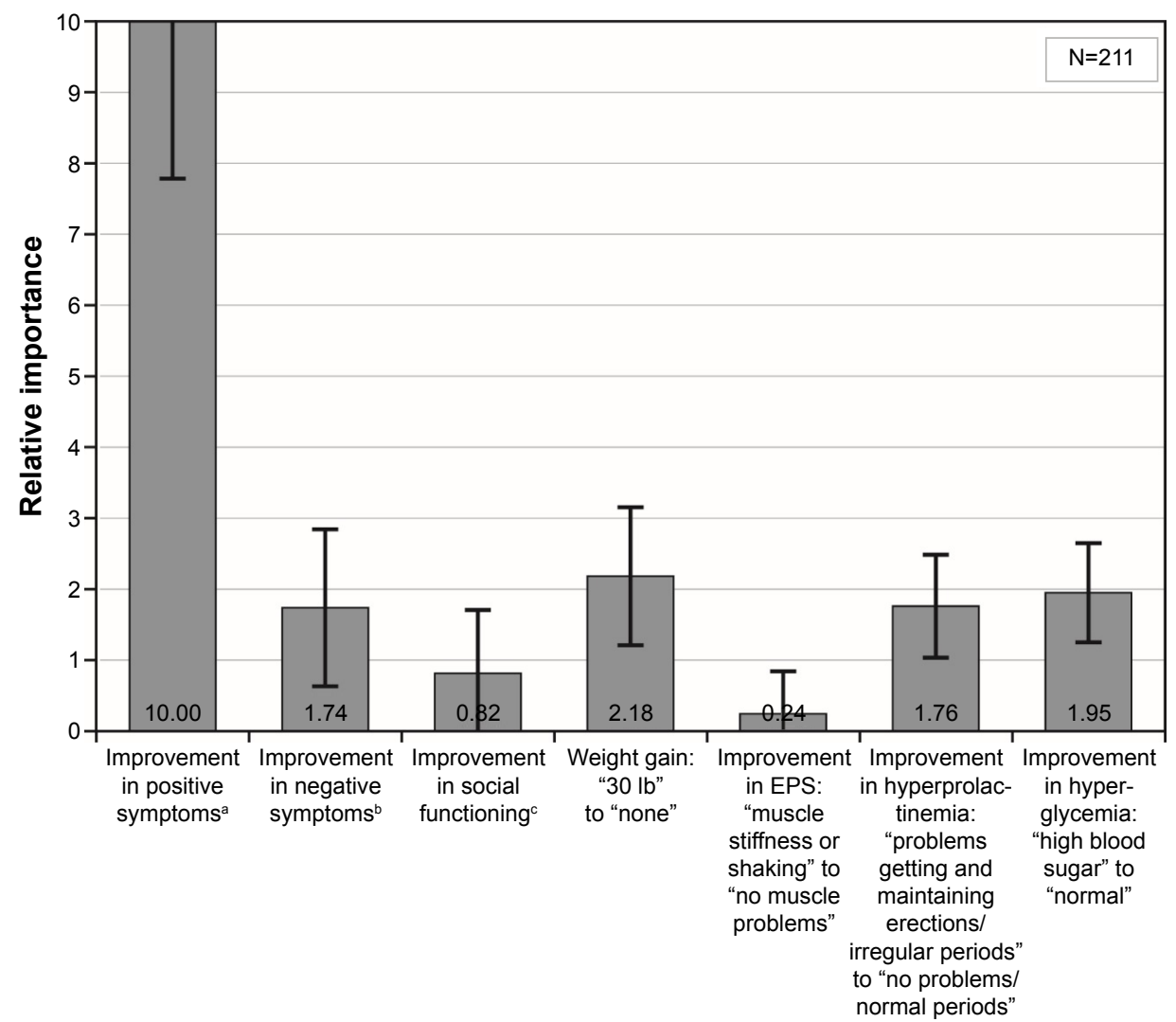

Figure 2 Preference weights for first series of choice questions for patients.

Notes: annusual beliefs, hearing voices, and not trusting people to no unusual beliefs; bdifficulty in speaking with others or showing emotions to speaks normally and has emotions; 'decreased interest in social activities to less interest in social activities. Each bar represents the improvement in utility associated with switching from the least preferred to the most preferred level of each attribute. The vertical bars surrounding each mean preference weight denote the $95 \% \mathrm{Cl}$ about the point estimate.

Abbreviations: $\mathrm{Cl}$, confidence interval; EPS, extrapyramidal symptoms; $\mathrm{N}$, number of respondents who answered the question.

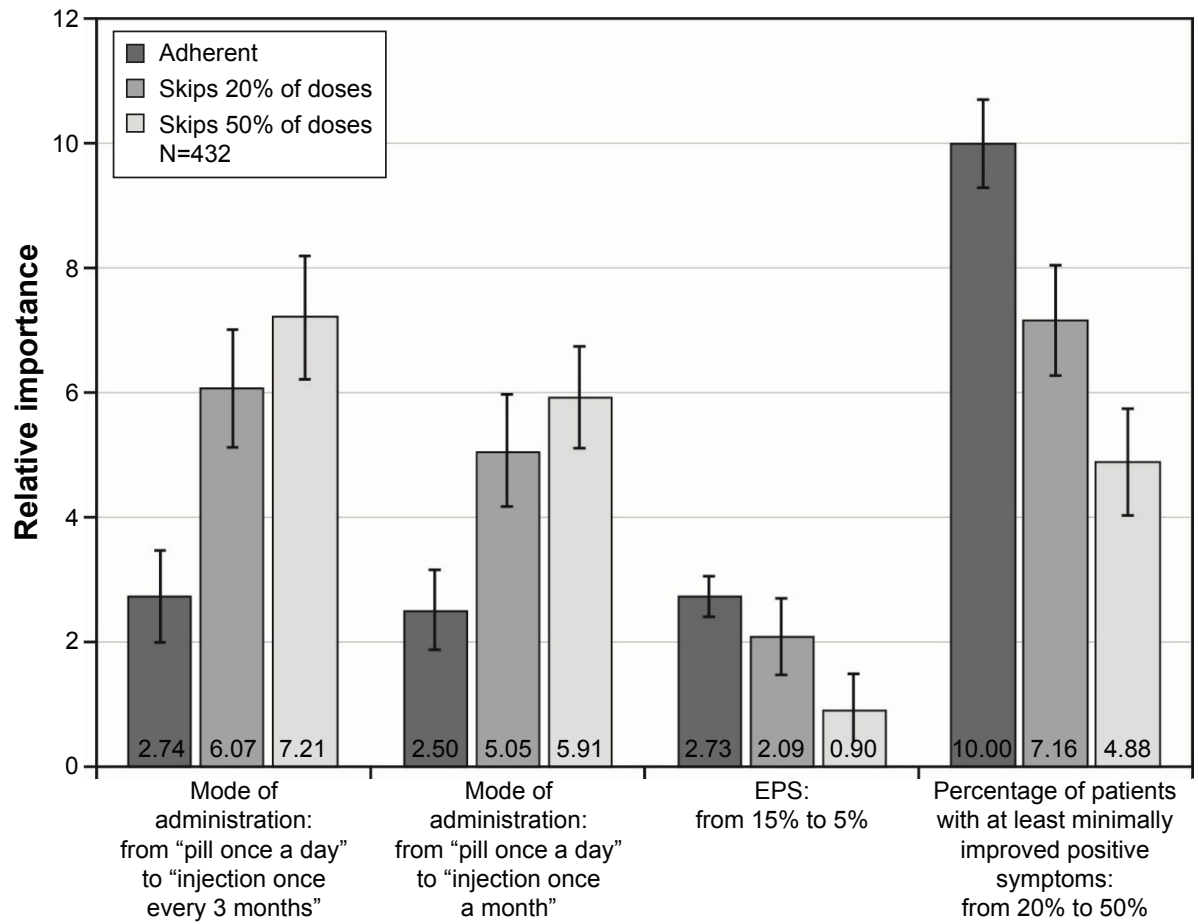

Figure 3 Relative importance assigned by physicians in second series of choice questions.

Note: The vertical bars surrounding each mean preference weight denote the $95 \% \mathrm{Cl}$ about the point estimate.

Abbreviations: $\mathrm{Cl}$, confidence interval; EPS, extrapyramidal symptoms; $\mathrm{N}$, number of respondents who answered the question. 


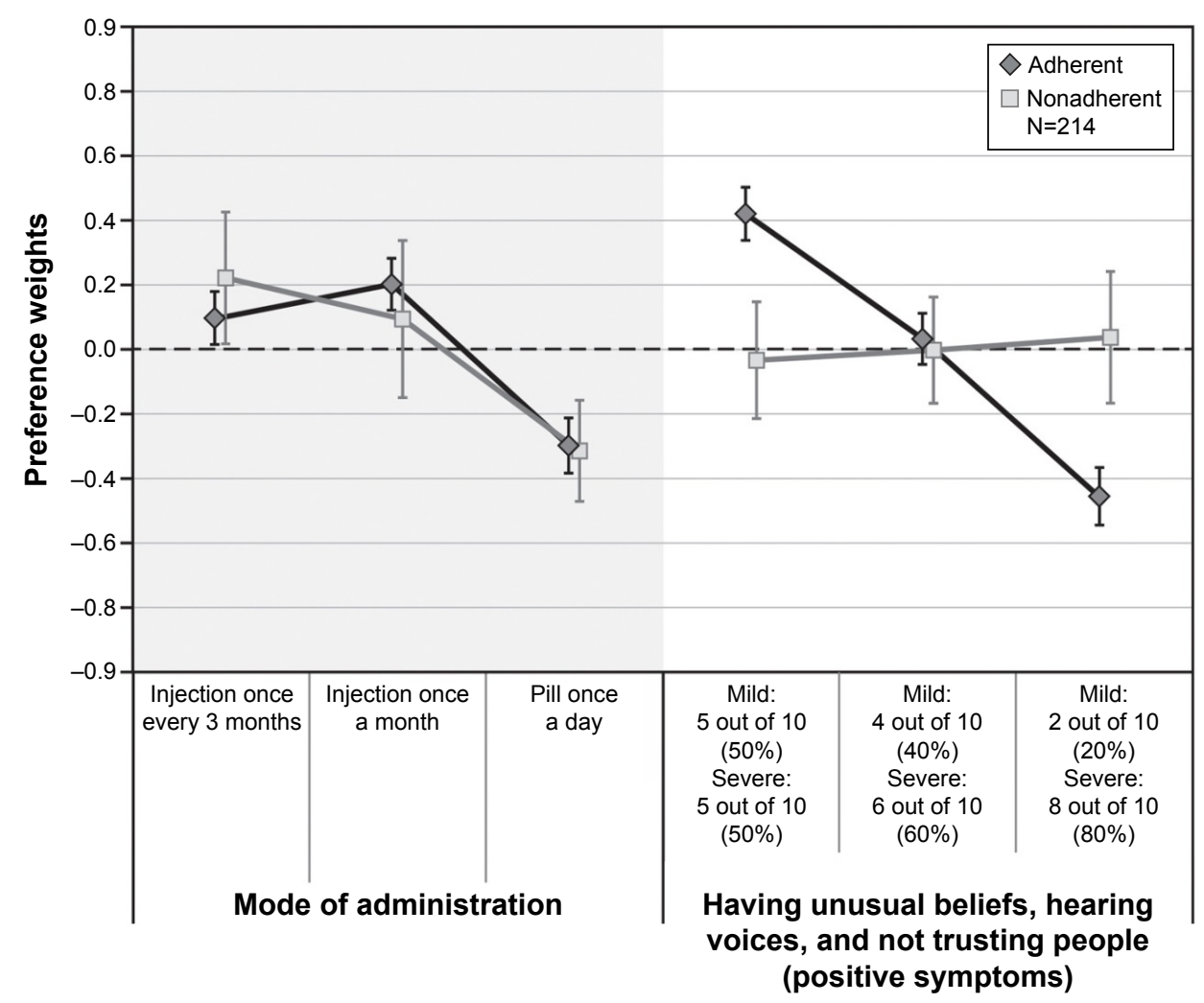

Figure 4 Relative importance assigned by patients to second series of choice questions.

Notes: A line plot is used here, rather than a bar plot, since the preference changes are not monotonic and cannot be represented by single bars. The vertical bars surrounding each mean preference weight denote the $95 \% \mathrm{Cl}$ about the point estimate.

Abbreviations: $\mathrm{Cl}$, confidence interval; $\mathrm{N}$, number of respondents who answered the question.

in the percentage of patients with at least minimally improved positive symptoms (efficacy). For 20\% nonadherent (missing 20\% doses) and 50\% nonadherent (missing 50\% doses) patients, the maximum acceptable decrease in efficacy was $21.2 \%$ (95\% CI: $17.3-25.0)$ and 35.6\% (95\% CI: $27.8-43.4)$, respectively. Similarly, in exchange to switching from a daily oral to a 3-month LAI, physicians would be willing to accept a reduction in efficacy of $9.8 \%$ (95\% CI: 7.2-12.4), 25.4\% (95\% CI: $21.0-29.9$ ), and $>30 \%$ for adherent, $20 \%$ nonadherent, and $50 \%$ nonadherent patients, respectively. While the formal calculation of maximum acceptable risk for adherent patients yields $42.8 \%$ (95\% CI: 33.3-52.4), because the survey only considered a range of efficacy from $20 \%$ to $50 \%$ chance of minimal improvement, it is not possible to state the maximum acceptable risk beyond this range of $30 \%$.

\section{Patients}

The adherence choice tasks enquired about nonadherence at two levels: missing $20 \%$ and $50 \%$ of doses; there was no difference between these results, which were pooled and referred to as nonadherent.

For both adherent and nonadherent patients, both 1-month and 3-month LAIs were preferred to daily pills $(P<0.05)$.
Differences in preference between 1-month and 3-month LAIs were not significant (Figure 4). When adherence and efficacy were jointly assessed, respondents clearly valued increasing efficacy for a hypothetical adherent patient, ie, increasing the percentage of patients with mild versus severe positive symptoms. However, for a nonadherent patient, the differences in preference weights were very small, slightly disordered, and not statistically significantly different, suggesting that respondents saw little value in improvements in the probability of efficacy for nonadherent patients.

For a patient switching from a daily oral to a 3-month LAI, the maximum acceptable decrease in efficacy was 10.1\% (95\% CI: 6.1-14.1) for adherent patients. As patients placed no value on improving efficacy over the range assessed in the survey for a nonadherent patient, estimation of maximum acceptable decrease in efficacy was not possible to determine.

\section{Discussion}

An understanding of patient and physician priorities regarding treatment, and a patient's active involvement in selecting a disease management strategy, is important in regulatory decisions, in clarifying acceptable medical options, and in 
choosing an appropriate treatment. ${ }^{12,29}$ This is the first time a DCE for both patients and physicians has been successfully incorporated into a clinical trial, and it may play an important role in the assessments of patients' and physicians' preferences in future clinical studies.

Physicians and patients placed the greatest importance on improvement in positive symptoms. Although improvements in positive symptoms were the main feature that drove patients' preferences, physicians regarded total improvement in negative symptoms and social functioning as at least 50\% as important as total improvement in positive symptoms. While the rationale behind the measured relative importance scores was not studied, one possible explanation is that patients may understand the dangers associated with severe positive symptoms, while physicians' first concern might be stabilizing a psychotic patient, considering that AEs are much more manageable by adjusting the dose and choice of antipsychotic.

In this survey, both physicians and patients preferred LAIs to a daily oral medication. Physicians judged LAIs superior to daily pills regardless of patient's degree of adherence $(P<0.05)$, with greater preference for the 3 -month over 1-month LAI for nonadherent patients. As adherence decreased, physician preference for the LAIs increased, and physicians would accept a decrease in efficacy in exchange for switching a patient from a daily oral to a LAI. Patients also preferred a LAI over a daily pill for both adherent and nonadherent patients, with no significant difference observed between 1-month and 3-month LAIs.

Patients were indifferent to changes in the probability of efficacy (mild vs severe positive symptoms) over the $20 \%-50 \%$ range, assessed when making judgments about nonadherent patients, while they regarded such changes as important for adherent patients. In contrast, physicians regarded improvements in the probability of efficacy as important, regardless of the adherence level. While the survey did not address the motivation behind their choices, these results suggest that patient's judge adherence as critical in treatment decisions. These results also indicate the importance of including adherence when conducting DCEs for indications where adherence is a known concern.

The findings of this study were comparable with those of pilot studies and other published studies..$^{18,19,30,31}$ In those studies, respondents (physicians and/or patients) rated improvements in positive symptoms and social functioning as more important than improvement in negative symptoms and avoidance of AEs..$^{18,19,30,31}$ Recent studies assessing patient and physician judgments about medications' benefits and risks have shown that both made treatment decisions primarily on the basis of improvement in positive symptoms..$^{19,32}$

There were several important limitations of this study. This survey measured and quantified preferences across benefits, risks, and mode of treatment administration, but these studies typically do not study the rationale behind respondent decisions. Also, the survey was designed to allow respondents to interpret the attributes consistently and as intended. However, it is not possible to prove consistent interpretation by respondents. Evaluation of choice tasks could be cognitively difficult for respondents, although the training section of the survey provided details on attribute definitions and practice questions, and the same instruments have been used successfully in earlier studies. ${ }^{18,19}$ Additionally, stated preference confronts respondents with hypothetical scenarios, and the choices indicated by patients do not have the same impact as the actual decisions. Hence, there was a potential for hypothetical bias.

Additional limitations were constraints on cognition that restricted the number of end points and levels of those end points that could be considered simultaneously by survey respondents. For reasons given previously, ${ }^{18,19}$ the levels of social functioning did not include "no symptoms" or "complete cure" level unlike positive and negative symptoms. If the full range of social functioning were incorporated, it might have shown greater importance than negative symptoms. These surveys were not designed to address the question of whether judgments would change depending on the experience with a particular AE. The survey assessed judgment, which is distinct from personal preference or choice. Schizophrenia patients are very sensitive about revealing their personal information, and prior surveys demonstrated that such patients answer hypothetical questions about judgments more easily than preferences. ${ }^{17}$ Formulating the questions as judgments also avoided confusion with patients' experiences and expectations about how treatments could affect their own emotional responses, encouraged objectivity, and reduced potential bias compared with a question about what patients would choose for themselves. ${ }^{33,34}$

Finally, several factors may limit the representativeness and generalizability of the preference results. The patient survey was administered within a few English-speaking countries and the physician survey was administered within a diverse range of countries, each with varying clinical and cultural practices. Both patients and physicians chose to participate in a clinical trial and had to satisfy the specific criteria. For these reasons, the sample may have preferences that differ from the underlying populations. 


\section{Conclusion}

Preference surveys administered to trial participants and physician investigators of two phase-3, multinational clinical studies of LAI PP3M demonstrated that they appraised treatments primarily on the basis of improvement in positive symptoms. Both patients and physicians judged LAIs to be better than the oral formulation irrespective of patient's adherence, wherein physicians showed greater preference for the 3-month over 1-month LAI. Additionally, these results suggest the importance of determining patients' own preferences and physicians' judgments in regulatory decisions and, potentially, individual treatment decision-making.

\section{Acknowledgments}

The authors acknowledge Vaibhav Deshpande (SIRO Clinpharm Pvt. Ltd.) for writing support, Ashwini Patil, ISMPP CMPPTM (SIRO Clinpharm Pvt. Ltd., Thane, Maharashtra, India) for assistance with revisions and editorial support, and Ellen Baum (Janssen Research \& Development, LLC, Raritan, NJ, USA) for additional editorial support for the development of this manuscript. Janssen Research \& Development, LLC provided funding to RTI Health Solutions to conduct this study.

\section{Author contributions}

Drs Katz, Levitan, Gopal, Fairchild, Hauber, Pugh, and Weinstein contributed to the design of this study, data analysis, interpretation, and authorship. All authors met ICMJE criteria and all those who fulfilled those criteria are listed as authors. All authors had access to the study data, provided direction and comments on the manuscript, had final approval of the document, and made the final decision about where to publish these data.

\section{Disclosure}

Drs Katz, Gopal, Levitan, and Weinstein are employees of Janssen and hold company stocks. Dr Levitan is also a stockholder in Baxter International, Inc., Pharmaceutical Holdrs Trust, and Zimmer Holdings, Inc. He also owns stock in a variety of companies that at times include pharmaceutical and health care-related companies. Dr Hauber is an employee of RTI Health Solutions. Drs Pugh and Fairchild were employees of RTI Health Solutions at the time this study was conducted. The authors report no other conflicts of interest in this work.

\section{References}

1. Coppola D, Melkote R, Lannie C, et al. Efficacy and safety of paliperidone extended release $1.5 \mathrm{mg}$ /day-a double-blind, placebo- and active-controlled, study in the treatment of patients with schizophrenia. Psychopharmacol Bull. 2011;44(2):1-19.
2. Kane JM, Aguglia E, Altamura AC, et al. Guidelines for depot antipsychotic treatment in schizophrenia. European Neuropsychopharmacology Consensus Conference in Siena, Italy. Eur Neuropsychopharmacol. 1998;8(1):55-66.

3. Volavka J, Citrome L. Oral antipsychotics for the treatment of schizophrenia: heterogeneity in efficacy and tolerability should drive decisionmaking. Expert Opin Pharmacother. 2009;10(12):1917-1928.

4. Kienle GS, Kiene H. Clinical judgement and the medical profession. J Eval Clin Pract. 2011;17(4):621-627.

5. Bridges JF, Mohamed AF, Finnern HW, Woehl A, Hauber AB. Patients' preferences for treatment outcomes for advanced non-small cell lung cancer: a conjoint analysis. Lung Cancer. 2012;77(1):224-231.

6. Brett Hauber A, Mohamed AF, Beam C, Medjedovic J, Mauskopf J. Patient preferences and assessment of likely adherence to hepatitis $\mathrm{C}$ virus treatment. J Viral Hepat. 2011;18(9):619-627.

7. Mohamed AF, Hauber AB, Neary MP. Patient benefit-risk preferences for targeted agents in the treatment of renal cell carcinoma. Pharmacoeconomics. 2011;29(11):977-988.

8. Food and Drug Administration (FDA). The voice of the patient: a series of reports from FDA's Patient-Focused Drug Development Initiative. 2015. Available from: http://www.fda.gov/ForIndustry/UserFees/PrescriptionDrugUserFee/ucm368342.htm. Accessed February 25, 2016.

9. European Medicines Agency. The patient's voice in the evaluation of medicines. How patients can contribute to assessment of benefit and risk. 2013. Available from: http://www.ema.europa.eu/docs/en_GB/ document_library/Report/2013/10/WC500153276.pdf. Accessed September 8, 2015.

10. European Medicines Agency. Patients to discuss benefit - risk evaluation of medicines with the Committee for Medicinal Products for Human Use. 2014. Available from: http://www.ema.europa.eu/docs/ en_GB/document_library/Press_release/2014/09/WC500173511.pdf. Accessed 4 Jan 2016.

11. Health Canada, Government of Canada.Archived - Minister Ambrose announces patient involvement pilot for orphan drugs. 2014 Available from: http://news.gc.ca/web/article-en.do?mthd=tp\&crtr. page $=7 \&$ nid $=873619 \&$ crtr.tp1D=1. Accessed February 26, 2016.

12. Food and Drug Administration (FDA). Enhancing benefit-risk assessment in regulatory decision-making. 2014. Available from: http:/www. fda.gov/ForIndustry/UserFees/PrescriptionDrugUserFee/ucm 326192. htm. Accessed September 7, 2015.

13. Center for Devices and Radiological Health (CDRH). Patient preference information - submission, review in PMAs, HDE applications, and De Novo requests, and inclusion in device labeling Draft Guidance for industry, food and Drug Administration Staff, and other stakeholders. 2015. Available from: http:/www.fda.gov/ucm/groups/fdagovpublic/@fdagov-meddev-gen/documents/document/ucm446680.pdf. Accessed September 8, 2015.

14. Medical Device Innovation Consortium (MDIC). Patient Centered Benefit-Risk Project Report. 2015. Available from: http://mdic.org/wpcontent/uploads/2015/05/MDIC_PCBR_Framework_Proof5_Web.pdf. Accessed September 8, 2015.

15. Innovative Medicines Initiative (IMI). Europe 2 Programme: 5 th Call for proposals. 2015. Available from: http://www.imi.europa.eu/sites/ default/files/uploads/documents/IMI2Call5/IMI2_C5_PUBLICATION. pdf. Accessed 5 Jan 2016.

16. Revicki DA, Shakespeare A, Kind P. Preferences for schizophreniarelated health states: a comparison of patients, caregivers and psychiatrists. Int Clin Psychopharmacol. 1996;11(2):101-108.

17. Bridges JF, Kinter ET, Schmeding A, Rudolph I, Muhlbacher A. Can patients diagnosed with schizophrenia complete choice-based conjoint analysis tasks? Patient. 2011;4(4):267-275.

18. Levitan B, Markowitz M, Mohamed AF, et al. Patients' preferences related to benefits, risks, and formulations of schizophrenia treatment. Psychiatr Serv. 2015;66(7):719-726.

19. Markowitz MA, Levitan BS, Mohamed AF, et al. Psychiatrists' judgments about antipsychotic benefit and risk outcomes and formulation in schizophrenia treatment. Psychiatr Serv. 2014;65(9):1133-1139. 
20. Citrome L. New second-generation long-acting injectable antipsychotics for the treatment of schizophrenia. Expert Rev Neurother. 2013;13(7): 767-783.

21. Shuler KM. Approaches to improve adherence to pharmacotherapy in patients with schizophrenia. Patient Prefer Adherence. 2014;8: 701-714.

22. Kaplan G, Casoy J, Zummo J. Impact of long-acting injectable antipsychotics on medication adherence and clinical, functional, and economic outcomes of schizophrenia. Patient Prefer Adherence. 2013;7: 1171-1180.

23. Berwaerts J, Liu Y, Gopal S, et al. Efficacy and safety of the 3-month formulation of paliperidone palmitate vs placebo for relapse prevention of schizophrenia: a randomized clinical trial. JAMA Psychiatry. 2015; 72(8):830-839.

24. Savitz AJ, Xu H, Gopal S, et al. Efficacy and safety of paliperidone palmitate 3-month formulation for patients with schizophrenia: a randomized, multicenter, double-blind, noninferiority study. Int $J$ Neuropsychopharmacol. 2016;19(7). pii:pyw018.

25. Bridges JF, Hauber AB, Marshall D, et al. Conjoint analysis applications in health - a checklist: a report of the ISPOR Good Research Practices for Conjoint Analysis Task Force. Value Health. 2011;14(4): 403-413.

26. Hanemann M, Loomis J, Kanninen B. Statistical efficiency of doublebounded dichotomous choice contingent valuation. Am JAgric Econ. 1991; 73(4):1255-1263.

27. Johnson FR, Lancsar E, Marshall D, et al. Constructing experimental designs for discrete-choice experiments: report of the ISPOR Conjoint Analysis Experimental Design Good Research Practices Task Force. Value Health. 2013;16(1):3-13.
28. Hauber AB, Mohamed AF, Johnson FR, Falvey H. Treatment preferences and medication adherence of people with Type 2 diabetes using oral glucose-lowering agents. Diabet Med. 2009;26(4):416-424.

29. Mullard A. Patient-focused drug development programme takes first steps. Nat Rev Drug Discov. 2013;12(9):651-652.

30. Shumway M, Sentell T, Chouljian T, Tellier J, Rozewicz F, Okun M. Assessing preferences for schizophrenia outcomes: comprehension and decision strategies in three assessment methods. Ment Health Serv Res. 2003;5(3):121-135.

31. Shumway M, Saunders T, Shern D, et al. Preferences for schizophrenia treatment outcomes among public policy makers, consumers, families, and providers. Psychiatr Serv. 2003;54(8):1124-1128.

32. Markowitz M, Levitan B, Mohammed A. Psychiatrists' preferences for benefit and risk outcomes and formulation in schizophrenia treatments: a conjoint analysis study. Poster Presentation (PS5-05) at the Institute on Psychiatric Services; October 4-7; 2012; New York, NY.

33. Marta-Pedroso C, Freitas H, Domingos T. Testing for the survey mode effect on contingent valuation data quality: a case study of web based versus in-person interviews. Ecol Econ. 2007;62(3-4):388-398.

34. Nielsen JS. Use of the Internet for willingness-to-pay surveys: a comparison of face-to-face and web-based interviews. Resour Energy Econ. 2011;33(1):119-129. 


\section{Supplementary materials}

\begin{tabular}{|c|c|c|c|}
\hline & & Outcomes A & Outcomes B \\
\hline \multirow{3}{*}{ 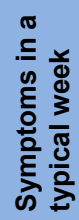 } & $\begin{array}{l}\text { Improvement in positive } \\
\text { symptoms }\end{array}$ & $\begin{array}{l}\text { Very much improved } \\
(80 \% \text { reduction })\end{array}$ & $\begin{array}{l}\text { No improvement } \\
\text { (<10\% reduction) }\end{array}$ \\
\hline & $\begin{array}{l}\text { Improvement in negative } \\
\text { symptoms }\end{array}$ & $\begin{array}{l}\text { No improvement } \\
\text { (<10\% reduction) }\end{array}$ & $\begin{array}{l}\text { Very much improved } \\
\text { (80\% reduction) }\end{array}$ \\
\hline & Social functioning & Mild problems & Moderate problems \\
\hline \multirow{4}{*}{ 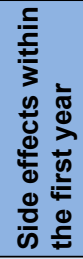 } & Weight gain & $15 \%$ & $7 \%$ \\
\hline & EPS & Yes & Yes \\
\hline & Hyperprolactinemia & No & Yes \\
\hline & Hyperglycemia & Yes & No \\
\hline \multicolumn{2}{|c|}{$\begin{array}{l}\text { Which set of outcomes is "better" } \\
\text { for the patient? }\end{array}$} & & \\
\hline
\end{tabular}

Figure SI Example of physician discrete-choice question (first set). Abbreviation: EPS, extrapyramidal symptoms.

\begin{tabular}{|c|c|}
\hline Pat's outcomes on medicine A & Pat's outcomes on medicine B \\
\hline - Thinks people are stealing from them & - No unusual beliefs \\
\hline - Often hears voices & - Does not hear voices \\
\hline - Does not trust people & - Trusts people \\
\hline - Speaks rarely and slowly & - Speaks briefly \\
\hline - Rarely shows emotion & - Does not laugh \\
\hline $\begin{array}{l}\text { - Less interest in social activities (noticed } \\
\text { by family or close friend) }\end{array}$ & - No interest in social activities \\
\hline $15 \mathrm{lb}$ weight gain over the past year & No weight gain over the past year \\
\hline Muscle stiffness or shaking & No muscle problems \\
\hline Normal periods & Irregular periods \\
\hline Has high blood sugar that can lead to diabetes & Normal blood sugar \\
\hline
\end{tabular}

Which medicine is "better" for Pat?

\begin{tabular}{|l|l|l|}
\hline Medicine A & Medicine B \\
\hline
\end{tabular}

Figure S2 Example of patient (female) discrete-choice question (first set). Abbreviation: Pat, patient. 


\begin{tabular}{|c|c|}
\hline Pat's outcomes on medicine A & Pat's outcomes on medicine B \\
\hline $\begin{array}{l}\text { - Thinks people are stealing from them } \\
\text { - Often hears voices } \\
\text { - Does not trust people } \\
\text { - Speaks rarely and slowly } \\
\text { - Rarely shows emotion } \\
\text { - Less interest in social activities (noticed } \\
\text { by family or close friend) }\end{array}$ & $\begin{array}{l}\text { - No unusual beliefs } \\
\text { - Does not hear voices } \\
\text { - Trusts people } \\
\text { - Speaks briefly } \\
\text { - Does not laugh } \\
\text { - No interest in social activities }\end{array}$ \\
\hline $\begin{array}{l}15 \mathrm{lb} \text { weight gain over the past year } \\
\text { Muscle stiffness or shaking } \\
\text { No problems with erections } \\
\text { Has high blood sugar that can lead to diabetes }\end{array}$ & $\begin{array}{l}\text { No weight gain over the past year } \\
\text { No muscle problems } \\
\text { Problems getting and maintaining erections } \\
\text { Normal blood sugar }\end{array}$ \\
\hline
\end{tabular}

Which medicine is "better" for Pat?

\begin{tabular}{|l|l|l|}
\hline Medicine A & Medicine B \\
\hline
\end{tabular}

Figure S3 Example of patient (male) discrete-choice question (first set). Abbreviation: Pat, patient.

\begin{tabular}{|c|c|c|}
\hline & Medication A (trial data) & Medication B (trial data) \\
\hline Mode of administration & Pill once a day & Injection once a month \\
\hline $\begin{array}{l}\text { Percent of patients with at } \\
\text { least minimally improved } \\
\text { ( } \geq 25 \% \text { reduction) positive } \\
\text { symptoms in a typical week, } \\
\text { compared to initial } \\
\text { presentation }\end{array}$ & 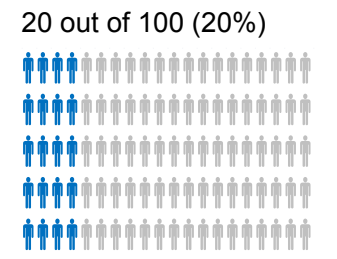 & 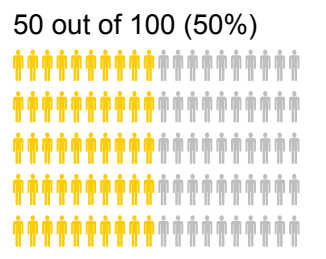 \\
\hline $\begin{array}{l}\text { Percent of patients with } \\
\text { EPS within the first year }\end{array}$ & 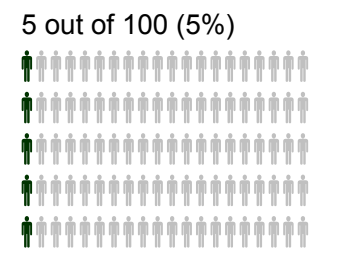 & 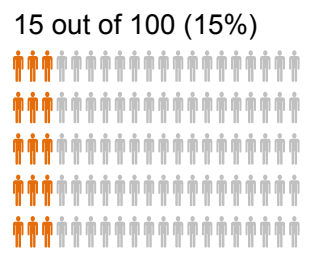 \\
\hline $\begin{array}{l}\text { Which treatment is "better" } \\
\text { for the patient? }\end{array}$ & & \\
\hline
\end{tabular}

New information: The patient has "missed or skipped $20 \%$ " of his or her doses of oral medication in the past.

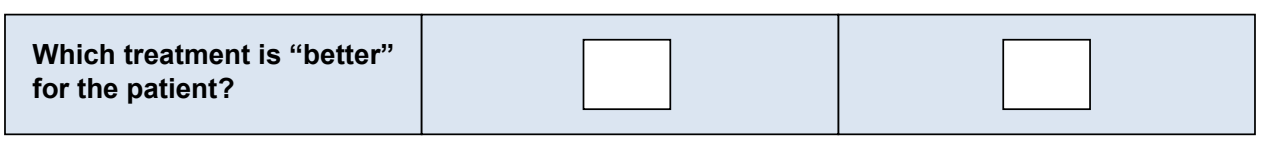

Figure S4 Example of physician formulation question with follow-up adherence information (second set). Abbreviation: EPS, extrapyramidal symptoms. 


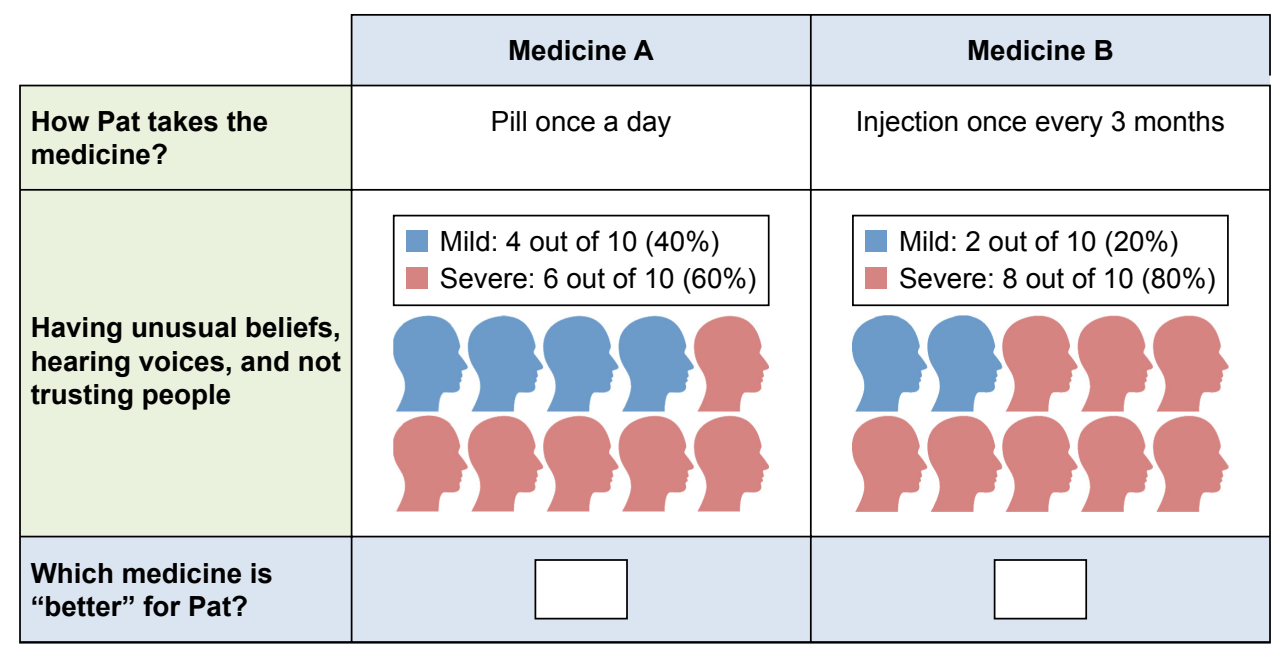

Now consider Jamie: Jamie is a patient like Pat who agrees with your choice above, but Jamie misses her pills once or twice a week.

\begin{tabular}{|l|l|l|}
\hline $\begin{array}{l}\text { Which medicine is } \\
\text { "better" for Jamie? }\end{array}$ & $\square$ & \\
\hline
\end{tabular}

Figure S5 Example of patient formulation question with follow-up adherence information (second set).

Notes: Medicines are the same except as shown in the figure. Pat typically never misses taking her medicine.

Abbreviation: Pat, patient.

\section{Publish your work in this journal}

Patient Preference and Adherence is an international, peer-reviewed, open access journal that focuses on the growing importance of patient preference and adherence throughout the therapeutic continuum. Patient satisfaction, acceptability, quality of life, compliance, persistence and their role in developing new therapeutic modalities and compounds to optimize clinical outcomes for existing disease states are major areas of interest for the journal. This journal has been accepted for indexing on PubMed Central. The manuscript management system is completely online and includes a very quick and fair peer-review system, which is all easy to use. Visit http://www. dovepress.com/testimonials.php to read real quotes from published authors.

\footnotetext{
Submit your manuscript here: http://www.dovepress.com/patient-preference-and-adherence-journal
} 